\title{
Thyroid Function Status in Indian Adult Nonpregnant Females in Ranchi, India
}

\author{
${ }^{1}$ Barun K Chakrabarty, ${ }^{2}$ Binay Mitra, ${ }^{3}$ Bhaskar Shahbabu, ${ }^{4}$ Nandita Hazra, ${ }^{5}$ Sarvinder Singh
}

\begin{abstract}
Aim: Thyroid disorders are one of the most common endocrine diseases in India. Thyroid disorders are more common in women than in men and contribute to significant morbidity. In this postiodization era, there is paucity of pan-Indian data of thyroid disorder status among adult nonpregnant women. This study was done to analyze the thyroid hormone levels in women of Jharkhand region, which is traditionally known to be an iodine-deficient area.
\end{abstract}

Materials and methods: Three hundred and forty nonpregnant adult females in Ranchi area who were consuming iodized salt formed part of the study group. Clinical evaluation was done by a gynecologist pertaining to thyroid illness. Thyroid function tests encompassing triiodothyronine, thyroxine, and thyroidstimulating hormone were carried out by quantitative enzyme immunoassay method. Thyroid status of the population was defined as per kit reference range.

Results: Subjects with age range 20 to 67 years were divided into three groups as per clinical status of thyroid disorder, viz. total, disease free, and control. A total of $19.6 \%$ had biochemical evidence of thyroid disorder and $82.4 \%$ were euthyroid as per reference ranges in kit literature. Out of hypothyroid subjects, $3.2 \%$ had clinical and $14.4 \%$ had subclinical hypothyroidism. In the study group, no subjects were detected to have overt or subclinical hyperthyroidism. Multiple comparison analysis was done with Statistical Package for the Social Sciences version 20.0, a statistical software package.

Discussion: This is the first study in Jharkhand area on nonpregnant adult female population that are getting iodine sufficient foods in an iodine-deficient region. The study showed high

\footnotetext{
${ }^{1}$ Graded Specialist, ${ }^{2}$ Classified Specialist, ${ }^{3}$ Medical Officer ${ }^{4,5}$ Senior Advisor

${ }^{1}$ Department of Pathology, Military Hospital, Ranchi, Jharkhand India

2Department of Gynecology and Obstetrics, Military Hospital Ranchi, Jharkhand, India

${ }^{3}$ Department of Community Medicine, Military Hospital, Ranchi Jharkhand, India

${ }^{4}$ Department of Pathology and Microbiology, Command Hospital Lucknow, Uttar Pradesh, India

${ }^{5}$ Department of Medicine and Pulmonary Medicine, Military Hospital, Ranchi, Jharkhand, India

Corresponding Author: Barun K Chakrabarty, Graded Specialist, Department of Pathology, Military Hospital, Ranchi Jharkhand, India, Phone: +917044648932, e-mail: bkcdc@ yahoo.co.in
}

prevalence of thyroid disorders in the study group. Hypothyroidism, predominantly subclinical hypothyroidism, is prevalent among women in this region.

Keywords: lodine sufficient, Nonpregnant adult female, Subclinical hypothyroidism, Thyroid disorders.

How to cite this article: Chakrabarty BK, Mitra B, Shahbabu B, Hazra N, Singh S. Thyroid Function Status in Indian Adult Nonpregnant Females in Ranchi, India. Indian J Med Biochem 2017;21(1):25-29.

\section{Source of support: Nil}

Conflict of interest: None

\section{INTRODUCTION}

Disorders of thyroid hormones are one of the most common endocrine diseases in India. Various studies projected that approximately 42 million population are affected by thyroid disorders in India. ${ }^{1}$ The prevalence and type of thyroid disorders depend on various factors like age, sex, ethnicity, geographical area, nutritional status, national policies, health care delivery system, and drug intake. Especially, the level of iodine intake in food is closely associated with pattern of thyroid disorders. ${ }^{2,3}$ The prevalence of thyroid disorders, both hypothyroidism and hyperthyroidism, is more common in women than in men. ${ }^{4}$ Clinical and subclinical forms of thyroid hormone disorders can contribute to morbidity in the form of infertility, menstrual irregularities, osteoporosis, hyperlipidemia, hypercholesterolemia, hyperhomocysteinemia, cardiovascular, and neuropsychiatry disease in female population. ${ }^{5,6}$ In this postiodization era when India is transforming from iodine-deficient to iodine sufficient stage, there is paucity of pan-Indian data of thyroid disorder status among women. ${ }^{7}$ There are only few comparable data available from Jharkhand. We undertook this study to provide data for total triiodothyronine (T3), total thyroxine (T4), and thyroid-stimulating hormone (TSH) in women of this region and evaluate their status of thyroid function.

\section{MATERIALS AND METHODS}

\section{Study Population}

All 340 nonpregnant adult women in Ranchi area who attended the 2-day thyroid profile camp organized by 492-bedded hospital. 


\section{Clinical Details}

Careful history was taken and clinical examination was done by a gynecologist pertaining to thyroid illness. All ladies were questioned in detail regarding consumption pattern of iodized salt. In the study, we presumed that our study population was iodine sufficient from the history of regular consumption of iodized salt during their stay in Ranchi with adequate knowledge of proper storage facilities.

\section{Categories of Population}

We have divided the study population into three groups, i.e., total population, disease-free, and control population following earlier studies, including the National Health and Nutrition Examination Survey (NHANES) III study to show the difference in range of thyroid hormones.

"Disease-free" population was selected by excluding subjects with known cases of thyroid disorder and with history of intake of antithyroid/thyroxin medication. "Control population" was selected by excluding the subjects with previous history of thyroid disorder and/or thyroid medication and those who clinically showed symptoms of hyper- or hypothyroidism and gives history of oral contraceptive pill (OCP)/breastfeeding. The "control population" was derived by applying the exclusion criteria on disease-free population, which included previous history of thyroid disorders, signs and symptoms of thyroid disorder, history of OCPs, history of breastfeeding, and pregnancy.

The study groups were made as per the models set by previous similar studies. ${ }^{8}$ From each participant, $5 \mathrm{~mL}$ of fasting venous blood was collected. The collected blood serum was separated and processed within maximum 3 hours of collection. Thyroid function tests comprising T3, T4, and TSH were carried out on all women.

Three hundred and forty nonpregnant adult women participated and formed the study group. The maximum number of individuals was in the 30 to 39 years age group $(60 \%)$. Of the total subjects $(n=340), 6 \%(n=19)$ had history of thyroid disease and/or use of thyroid medication. The remaining 321 participant females were defined as the "disease-free population." Also, 26 ladies (7\%) provide history of OCP intake and / or breastfeeding; 81 ladies (24\%) detected clinical signs and symptoms of thyroid disorders. The "control population" comprised 214 subjects.

\section{Laboratory Methods}

Serum T3, T4, and TSH assays were performed on readwell TOUCH microplate analyzer using commercially available enzyme-linked immunosorbent assay
(ELISA) kit BeneSphera ${ }^{\mathrm{TM}}$ (Avantor) by enzyme immunoassay quantitative method. ${ }^{9}$ The analytical sensitivity for T3 and T4 assays was $0.04 \mathrm{ng} / \mathrm{mL}$ and $0.4 \mu \mathrm{g} / \mathrm{dL}$ respectively. For TSH we followed 1 hour incubation procedure for which analytical sensitivity was $0.078 \mu \mathrm{IU} / \mathrm{mL}$. The inter- and intraassay reproducibility values for T3 assays were $8.9 \%$ for low serum range and $<5.5$ and $<7 \%$ respectively, for high serum range. Similarly, for T4, these values were 6.7 and $8.3 \%$ for low serum range and $<5 \%$ for high serum range respectively. For TSH, these values are $<5 \%$ for low serum range and $<6 \%$ for high serum range. The manufacturer kit literature provided reference intervals of T3, T4, and TSH as $0.52-1.85 \mathrm{ng} / \mathrm{mL}$, $4.8-11.6 \mu \mathrm{g} / \mathrm{dL}$, and $0.39-6.16 \mu \mathrm{IU} / \mathrm{mL}$, of which $\mathrm{T} 4$ value is specific for adult females.

\section{Data Analysis}

Hypothyroidism was classified as clinical if TSH was $>6.16 \mu \mathrm{IU} / \mathrm{mL}$ and total $\mathrm{T} 4 \mathrm{was}<4.8 \mu \mathrm{g} / \mathrm{dL}$ and subclinical if TSH was $>6.16 \mu \mathrm{IU} / \mathrm{mL}$ and total T4 was $>4.8 \mu \mathrm{g} /$ dL. Hyperthyroidism was classified as clinical if TSH was $<0.39 \mu \mathrm{IU} / \mathrm{mL}$ and total $\mathrm{T} 4$ was $>11.6 \mu \mathrm{g} / \mathrm{dL}$ and subclinical if TSH was $<0.39 \mu \mathrm{IU} / \mathrm{mL}$ and total T4 was $<11.6 \mu \mathrm{g} /$ dL. Euthyroid population are defined when TSH and T4 were within normal range value of kit. ${ }^{10}$

\section{Statistical Analysis}

Statistical analysis was performed using Microsoft Office "Excel 2010" with Windows 10 Operating System. For total T3 and total T4, we calculated the mean, standard deviation, and standard error. For TSH, we calculated the median, 2.5 and 97.5 percentiles. Multiple comparison analysis was done with the statistical software package, Statistical Package for the Social Sciences version 20.0 (SPSS Inc., USA).

\section{RESULTS}

Of the 340 total subjects in the age range 20 to 67 years, $205(60 \%)$ subjects were in 30 to 39 age group and mean age was $34.8 \pm 0.35$ years; $19.6 \%$ had biochemical evidence of thyroid disorder and $82.4 \%$ were euthyroid as per kit literature reference interval. Out of hypothyroid subjects, $3.2 \%$ had clinical and $14.4 \%$ had subclinical hypothyroidism (Table 1). In our study group, no subjects were detected to have overt or subclinical hyperthyroidism; 19 of the 340 women gave history of thyroid disorder or disorder-related medications. Of these, $16.5 \%$ showed biochemical evidence of hypothyroidism (10.5\% clinical, $26.3 \%$ subclinical). On excluding the 19 known cases of thyroid disorder from the total study group, a group of 321 subjects constituted the "disease-free population." 
Thyroid Function Status in Indian Adult Nonpregnant Females in Ranchi, India

Table 1: Characteristics of thyroid dysfunction in Ranchi study group

\begin{tabular}{|c|c|c|c|c|c|c|c|}
\hline \multirow{2}{*}{\multicolumn{2}{|c|}{ Study population }} & \multicolumn{2}{|c|}{ Total study group } & \multicolumn{2}{|c|}{ Disease-free study group } & \multicolumn{2}{|c|}{ Control group } \\
\hline & & $n$ & $\%$ & $n$ & $\%$ & $n$ & $\%$ \\
\hline \multicolumn{2}{|c|}{ Subjects with thyroid disorder } & 60 & 19.6 & 53 & 16.5 & 33 & 15.4 \\
\hline \multicolumn{2}{|c|}{ Euthyroid $^{a}$} & 280 & 82.4 & 268 & 83.5 & 181 & 84.6 \\
\hline \multirow[t]{2}{*}{ Hypothyroid } & Clinical $^{b}$ & 11 & 3.2 & 9 & 2.8 & 5 & 2.3 \\
\hline & Subclinical ${ }^{\mathrm{C}}$ & 49 & 14.4 & 44 & 13.7 & 28 & 13.1 \\
\hline
\end{tabular}

aEuthyroid: TSH 0.39-6.16 $\mu \mathrm{lU} / \mathrm{mL}$ and T4: 4.8-11.6 $\mu \mathrm{g} / \mathrm{dL} ;{ }^{\mathrm{b}}$ Clinical hypothyroidism: TSH >6.16 $\mu \mathrm{lU} / \mathrm{mL}, \mathrm{T} 4<4.8 \mu \mathrm{g} / \mathrm{dL} ;{ }^{\mathrm{c}}$ Subclinical hypothyroidism: TSH >6.16 $\mu \mathrm{lU} / \mathrm{mL}$, T4: $4.8-11.6 \mu \mathrm{g} / \mathrm{dL}$

Table 2: Serum levels of T3, T4, and TSH of total, disease-free, and control groups

\begin{tabular}{|c|c|c|c|c|c|c|c|}
\hline \multirow[b]{3}{*}{ Parameters } & & \multirow{2}{*}{$\begin{array}{l}\text { Age } \\
\text { Mean } \pm S D\end{array}$} & \multirow{2}{*}{$\begin{array}{l}\text { Mean } \pm S D \\
\end{array}$} & \multirow{2}{*}{$\begin{array}{l}\text { Mean } \pm S D \\
\text { Me }\end{array}$} & \multicolumn{3}{|c|}{$\mathrm{TSH}$} \\
\hline & & & & & Median & 2.5 percentile & 97.5 percentile \\
\hline & & Years & $n g / m L$ & $\mu g / d L$ & $\mu I U / m L$ & $\mu I U / m L$ & $\mu I U / m L$ \\
\hline Total $^{\mathrm{a}}$ & 340 & $34.81 \pm 6.45$ & $1.12 \pm 0.41$ & $7.7 \pm 1.88$ & 4.51 & 1.93 & 16.63 \\
\hline Disease free ${ }^{b}$ & 321 & $34.72 \pm 6.53$ & $1.12 \pm 0.41$ & $7.67 \pm 1.85$ & 4.47 & 1.88 & 12.79 \\
\hline Control $^{\mathrm{C}}$ & 214 & $35.33 \pm 5.64$ & $1.16 \pm 0.41$ & $7.81 \pm 1.78$ & 4.42 & 1.78 & 11.5 \\
\hline
\end{tabular}

anclusive of those with thyroid disease risk factors and medication; ${ }^{\text {b} E x c l u d e d ~ s u b j e c t s ~ w h o ~ r e p o r t e d ~ t h y r o i d ~ d i s o r d e r s ; ~}{ }^{\circ}$ Excluded subjects with thyroid disorder, thyroid disorder symptoms, on OCP and breastfeeding; SD: Standard deviation

Thyroid dysfunction was seen in $16.5 \%$, whereas $83.5 \%$ were euthyroid among this group, out of which $2.8 \%$ were clinically hypothyroid and $13.7 \%$ showed subclinical hypothyroidism (Table 1). After excluding subjects with clinical evidence of thyroid disorders (24\%), females with history of breastfeeding (6\%) and OCP (6\%), and 19 known cases from the total study population "control population" was obtained; $84.6 \%$ women in the "control population" were found to be biochemically euthyroid with the reference range provided by the kit manufacturer; $2.3 \%$ were found to be clinically hypothyroid and $13.5 \%$ were subclinical cases. There was no significant difference in the total T3 and T4 values between these three groups. There is statistically significant difference in TSH value between "control population" and total study population on bootstrapping $(\mathrm{p}=0.048)$. The T3, T4, and TSH values obtained in three study population groups in our study

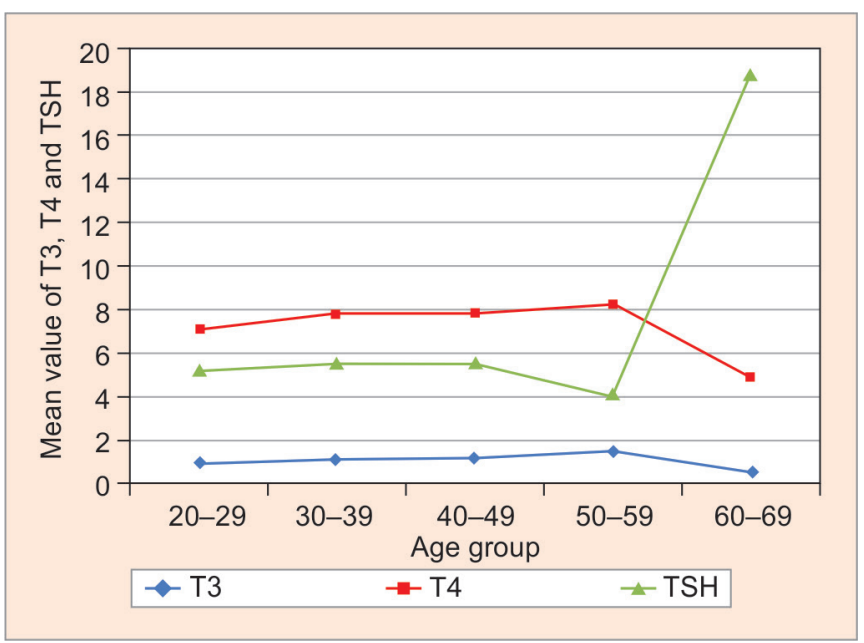

Graph 1: Mean serum T3, T4, TSH in total population at different age groups are shown in Table 2. All three study population showed statistically significant differences in T4 and TSH levels when compared with kit references, viz. total population [T4 ( $\mathrm{p}=0.00)$; TSH $(\mathrm{p}=0.001)]$, disease-free population [T4 $(p=0.00) ; \mathrm{TSH}(\mathrm{p}=0.001)]$, and control population [T4 $(p=0.002) ; \mathrm{TSH}(\mathrm{p}=0.001)]$. On linear regression analysis within control population, it was found that with one unit increase in age there is a 0.181 increase in T4 level and it is statistically significant $(\mathrm{p}=0.008)$. But for TSH values, there is no significant differences with age on linear regression analysis within control population $(\mathrm{p}=0.608)$. Comparative line diagram showing the relation of age groups with mean value of T3, T4, and TSH has been shown in three different study population, viz. total population (Graph 1), disease-free population (Graph 2), and control population (Graph 3). A total of 81 females (24\%) with clinical signs and symptoms of thyroid disorder and

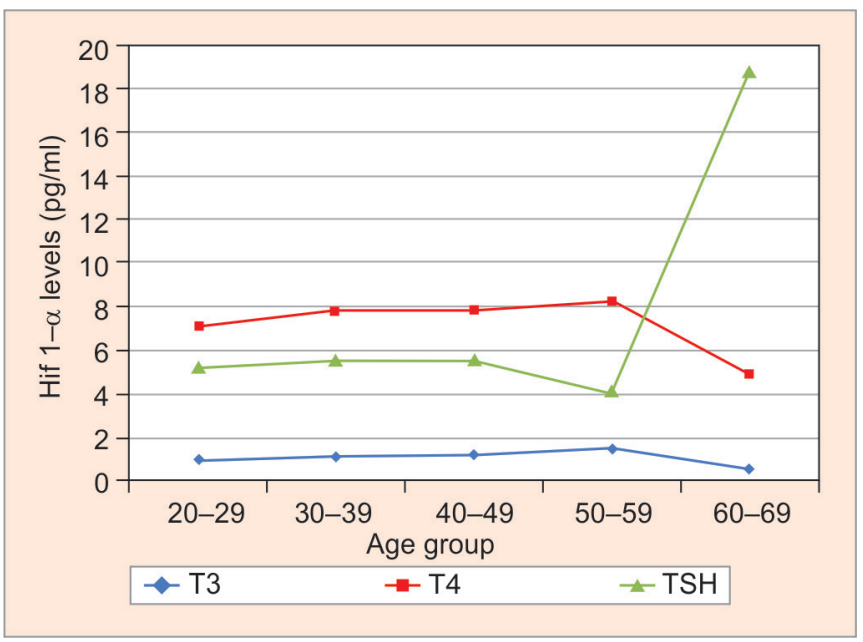

Graph 2: Mean serum T3, T4, and TSH in disease-free population at different age groups 


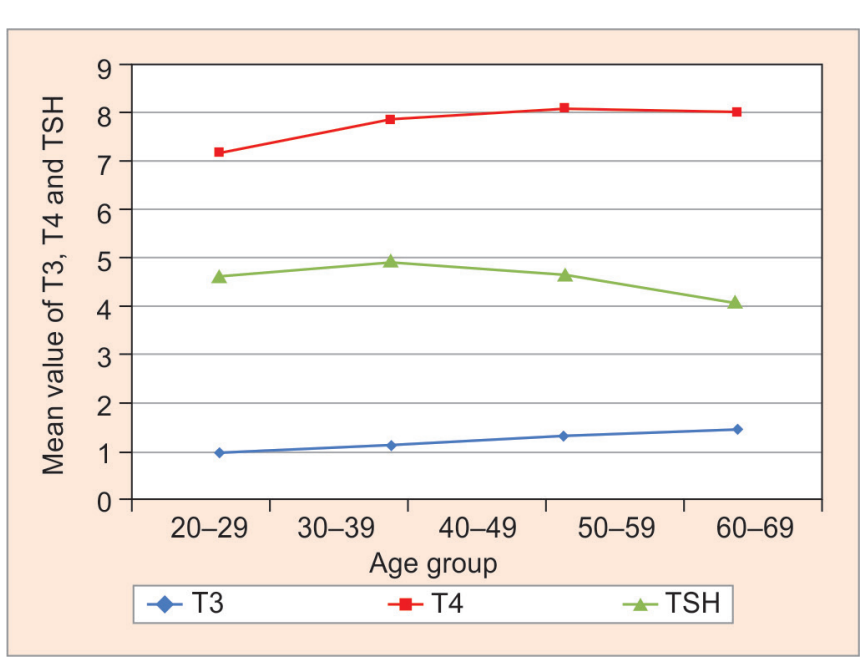

Graph 3: Mean serum T3, T4, and TSH in control population at different age groups

26 females $(7 \%)$ with history of OCP intake and breastfeeding showed statistically significant differences in $\mathrm{T} 4$ and TSH levels when compared with kit reference values.

\section{DISCUSSION}

The World Health Organization classified India as having optimal iodine nutrition based on assessment of global iodine status in $2004 .{ }^{11}$ Jharkhand is one of the least developed and iodine-deficient state in India. Due to various geographical features, the state has low soil iodine content, which is proven by a study. ${ }^{12}$ It is now a proven fact that females are more affected by thyroid disorders than males. ${ }^{4}$ Also, it has been shown that the physiological conditions like pregnancy can alter the thyroid hormone levels and thyroid hormone reference range for children and pregnant mothers is different. ${ }^{13}$ In our study, we have selectively excluded pregnant ladies. To get the thyroid hormone values in control nonpregnant women, we have excluded persons who are breastfeeding or taking OCPs. Various researches have been conducted to find out the prevalence of thyroid disorder in different states of India, but it appears that there has been very few studies carried out in Jharkhand area. ${ }^{1,14}$ It is wrongly believed that in this postiodization era, economically, educationally, and healthwise better Indian adult nonpregnant female population residing in Jharkhand do not suffer from thyroid disorders as they consume better planned food, which is believed to be rich in iodine. Our study is the first in this area on nonpregnant adult female population, most of whom are migrants and are getting iodine sufficient foods in an iodine-deficient region. The study showed prevalence of thyroid disorders in $20.7 \%$ females in Jharkhand area. ${ }^{15}$ In our study, we found that the prevalence rate of thyroid disorders is $19.6 \%$. Even in control adult female group in our study, $15.4 \%$ population was detected with biochemical evidence of hypothyroidism. In a prevalence study on thyroid disorders in women of Puducherry, $15.8 \%$ females were found to be affected and $13.3 \%$ were detected as hypothyroid. ${ }^{4}$ In a recent multicity study, the prevalence of overt undiagnosed clinical hypothyroidism was 3.5\% and that of subclinical hypothyroidism was $8.5 \% .{ }^{16}$ In the Puducherry study, $12.5 \%$ of women who are in the age group above 55 years had subclinical hypothyroidism. ${ }^{4}$ In our study, $13 \%$ of the women who are above 40 years of age showed biochemical evidence of subclinical hypothyroidism. The prevalence of clinical and subclinical hypothyroidism was much higher among 19 women (36.8\%) who had previous history of thyroid disorder or were under thyroid medication. These data are comparable to the Colorado study and the NHANES III study, where only 60 and $67 \%$ respectively, of study subjects under thyroid medication were found to be appropriately treated. ${ }^{8,17}$ Our study showed the higher age group had high TSH and low T3 and T4. The Whickham Survey in Britain and NHANES III data showed that the rise in TSH level with age in females was related to increased presence of antithyroid antibodies. ${ }^{8,18}$ In our study, there was a statistically significant difference seen in TSH and T4 levels in all three study groups when compared with kit reference range.

Both clinical hyper- and hypothyroidism cause a variety of clinical symptoms and should be adequately treated. However, diagnosis and management of subclinical thyroid disorder remains controversial. It has been reported that subclinical hyperthyroidism is a risk factor for various disorders, particularly in adult nonpregnant females. ${ }^{19}$

Our laboratory assays were done by most commonly used and economical ELISA method, using suitable calibrated instrument and standard kits. Tests were validated and performed using precise and accurate methods with appropriate quality control procedures. The statistical strengths are analyzed by distribution examination, using proper parametric or nonparametric methods.

The important limitation of our study is the normal reference range used for the hormonal assay, which was provided by the kit manufacturers as we have no specific reference range for our study population; secondly, the patients were not assayed for free T3 (FT3), free T4 (FT4), and antithyroid antibodies due to economic constraints. Another limitation of our study is that we presumed that our study population was iodine sufficient from the history of regular consumption of iodized salt, without evaluating for dependable indicators, such as iodine content measurement in salt samples or urinary iodine content or taking further history of proper utilization techniques of iodized salt. ${ }^{20}$ Nowadays, various other 
sensitive and precise methods are available for thyroid hormone assays and ELISA is not considered a good technique for immunoassays due to many subjective variation. But as it is a very economical and most widely used technique in a country like India, we have used robust quality control measures and best trained manpower to avoid the limitations of ELISA.

This is the first study conducted in postiodization era on pan-Indian, relatively healthy, economically stable nonpregnant adult female population. It is also the first study from Jharkhand, Eastern India, on similar population group with respect to thyroid disorders. This study demonstrates that hypothyroidism, mainly subclinical hypothyroidism, is still now alarmingly high in the concerned population. This indicates that thyroid disease should be considered during routine evaluation of this susceptible group and should be followed by appropriate detection and treatment. The finding that a large number of control women unknowingly have laboratory evidence of thyroid dysfunction supports the usefulness of screening for early detection. The causes for the high prevalence of thyroid disorder in pan-Indian population with adequate history of intake of iodized food need to be searched for. Studies discussed, but not convincingly, the theory of emergence of thyroid autoimmunity due to iodine supplementation. ${ }^{21}$ In control women where biochemical evidence of hypothyroidism is detected, further research may determine whether treatment of subclinical hypothyroidism will benefit in preventing adverse health outcomes. Our study suggested that despite iodization, the prevalence of thyroid disorder has not dramatically decreased. Further studies are recommended in a larger cross-section of adult nonpregnant women in this region, including environmental and etiological factors like role of goitrogens, autoimmunity, medications, iodine, and nonthyroidal illness for better diagnosis and management of thyroid illness.

\section{REFERENCES}

1. Unnikrishnan AG, Menon UV. Thyroid disorders in India: an epidemiological perspective. Indian J Endocrinol Metab 2011 Jul;15(Suppl 2):S78-S81.

2. Velayutham K, Selvan SS, Unnikrishnan AG. Prevalence of thyroid dysfunction among young females in a south Indian population. Indian J Endocrinol Metab 2015 Nov-Dec; 19(6):781-784.

3. Sun X, Shan Z, Teng W. Effects of increased iodine intake on thyroid disorders. Endocrinol Metab 2014 Sep;29(3):240-247.

4. Abraham R, Srinivasa Murugan V, Pukazhvanthen P, Sen SK. Thyroid disorders in women of Puducherry. Indian J Clin Biochem 2009 Jan;24(1):52-59.

5. Mansourian AR. Female reproduction physiology adversely manipulated by thyroid disorders: a review of literature. Pak J Biol Sci 2013 Mar 1;16(3):112-120.
6. LeGrys VA, Funk MJ, Lorenz CE, Giri A, Jackson RD, Manson JE, Schectman R, Edwards TL, Heiss G, Hartmann KE. Subclinical hypothyroidism and risk for incident myocardial infarction among postmenopausal women. J Clin Endocrinol Metab 2013 Jun;98(6):2308-2317.

7. Pandav CS. Evolution of iodine deficiency disorders control program in India: a journey of 5,000 years. Indian J Public Health 2013 Jul-Sep;57(3):126-132.

8. Hollowell JG, Staehling NW, Flanders WD, Hannon WH, Gunter EW, Spencer CA, Braverman LE. Serum TSH, T(4), and thyroid antibodies in the United States population (1988 to 1994): National Health and Nutrition Examination Survey (NHANES III). J Clin Endocrinol Metab 2002 Feb;87(2): 489-499.

9. Chopra IJ, Solomon DH, Ho RS. A radioimmunoassay of thyroxine. J Clin Endocrinol Metabol 1971 Nov;33(5):865-868.

10. Guber HA, Farag AF. Evaluation of endocrine function. In: McPherson RA, Pincus MR, editors. Henry's clinical diagnosis and management by laboratory methods. 23rd ed. United States: Elsevier - Health Sciences Division; 2016 May 20.p. 373

11. WHO. Iodine Status Worldwide, WHO Global Database on Iodine Deficiency. Geneva: Department of Nutrition for Health and Development, WHO 2004.

12. Pandav C, Patro B, Saboth P, Zodpey S, Shukla A, Karmarkar M. Tracking progress toward elimination of iodine deficiency disorders in Jharkhand, India. Indian J Community Med 2008 Jul;33(3):182-185.

13. Marwaha R, Chopra S, Gopalakrishnan S, Sharma B, Kanwar R, Sastry A, Singh S. Establishment of reference range for thyroid hormones in normal pregnant Indian women. BJOG 2008 Mar 7;115(5):602-606.

14. Tayal D, Goswami B, Gupta N, Chawla R, Gupta VK, Singh B, Chawla A. Prevalence of thyroid disorders in patients visiting a tertiary care center in New Delhi: a three-year study. Asian J Med Sci 2012;3(4):15-23.

15. Prasad A, Kumari T, Sinha KK, Bharti ML. Proportion of thyroid diseases in Jharkhand. Int J Pharm Sci Res 2016;(36):3843-3847.

16. Unnikrishnan A, Bantwal G, John M, Kalra S, Sahay R, Tewari N. Prevalence of hypothyroidism in adults: an epidemiological study in eight cities of India. Indian J Endocrinol Metab 2013 Jul;17(4):647-652.

17. Canaris GJ, Manowitz NR, Mayor G, Ridgway EC. The Colorado thyroid disease prevalence study. Arch Intern Med 2000 Feb 28;160(4):526-534.

18. Tunbridge WM, Evered DC, Hall R, Appleton D, Brewis M, Clark F, Evans JG, Young E, Bird T, Smith PA. The spectrum of thyroid disease in a community: the Whickham survey. Clin Endocrinol 1977 Dec;7(6):481-493.

19. Bjoro T, Holmen J, Kruger O, Midthjell K, Hunstad K, Schreiner T, Sandnes L, Brochmann H. Prevalence of thyroid disease, thyroid dysfunction and thyroid peroxidase antibodies in a large, unselected population. The health study of Nord-Trondelag (HUNT). Eur J Endocrinol 2000 Nov 1;143(5):639-647.

20. WHO/UNICEF/ICCIDD. Indicators for assessing iodine deficiency disorders and their control through salt iodization. Geneva: WHO/NUT/94.6; 1994.

21. Harach HR, Escalante DA, Saravia E. Thyroid cancer and thyroiditis in Salta, Argentina: a 40-yr study in relation to iodine prophylaxis. Endocr Pathol 2002 Fall;13(3):175-181. 